\title{
Comparison of Computed and Measured Vortex Evolution for a UH-60A Rotor in Forward Flight
}

\author{
Jasim U. Ahmad ${ }^{\mathrm{a}}$, Gloria K. Yamauchib, David L. Kao ${ }^{\mathrm{c}}$ \\ NASA Ames Research Center, Moffett Field, CA 94035
}

\begin{abstract}
A Computational Fluid Dynamics (CFD) simulation using the Navier-Stokes equations was performed to determine the evolutionary and dynamical characteristics of the vortex flowfield for a highly flexible aeroelastic UH-60A rotor in forward flight. The experimental wake data were acquired using Particle Image Velocimetry (PIV) during a test of the fullscale UH-60A rotor in the National Full-Scale Aerodynamics Complex 40- by 80-Foot Wind Tunnel. The PIV measurements were made in a stationary cross-flow plane at 90 deg rotor azimuth. The CFD simulation was performed using the OVERFLOW CFD solver loosely coupled with the rotorcraft comprehensive code CAMRAD II. Characteristics of vortices captured in the PIV plane from different blades are compared with CFD calculations. The blade airloads were calculated using two different turbulence models. A limited spatial, temporal, and CFD/comprehensive-code coupling sensitivity analysis was performed in order to verify the unsteady helicopter simulations with a moving rotor grid system.
\end{abstract}

\section{Introduction}

$\mathrm{H}$ gh-fidelity Computational Fluid Dynamics (CFD) and Computational Structural Dynamics (CSD) simulations are required to accurately model the vortical helicopter flowfield. The helicopter flowfield consists of unsteady aerodynamics with a complex three-dimensional wake. The wake is highly dominated by blade tip vortices, and in the case of the UH-60A rotor vortices are also shed from the edges of the trim tab ${ }^{1}$. The wake also contains shear layers that are produced as the turbulent boundary layers detach from the blade surfaces. As the tip vortices convect, the vortex cores entrain part of the shear layers.

The accurate simulation of vortex characteristics and convection is critical for predicting airloads, aeroacoustics, near-wake effects, and far-wake characteristics. Numerous studies have investigated the vortex evolution and vortex interaction with the blade trailed shear layer. Numerical solutions for such flows require a large number of grid points and long time integration. Many references, including simulation ${ }^{2-3}$ using the OVERFLOW ${ }^{4}$, code address grid related issues and validation for the UH-60A flowfield.

Acquiring accurate data for validating modern simulation tools is one of the goals of the NASA Rotary Wing (RW) Project, which is part of NASA's Fundamental Aeronautics Program. The full-scale UH-60A Airloads wind tunnel test conducted in May 2010 was a key experiment providing a comprehensive data set for tool validation ${ }^{5}$. Measurements included blade airloads, blade structural loads, rotor performance, and blade deformations. In addition, rotor wake characteristics were measured using the Particle Image Velocimetry (PIV) technique ${ }^{1,6}$. The current study uses data from one test condition for comparison with OVERFLOW computational results.

Another goal of the RW Project is to enhance physics-based computational tools. OVERFLOW is a state-of-theart CFD code developed at NASA that solves the time-dependent Reynolds-averaged Navier-Stokes (RANS) equations with Detached Eddy Simulation (DES) option using generalized curvilinear coordinates and overset grids. OVERFLOW has options for higher-order differencing of the convective flux derivatives, which have been evaluated for rotor problems $\mathrm{s}^{2-3}$. These higher-order differencing help reduce vortex diffusion and dispersion error. OVERFLOW has been loosely coupled with the CAMRAD II ${ }^{7}$ helicopter comprehensive code to take advantage of CAMRAD's CSD and trim capability. The work reported here simulates a flexible rotor flowfield using high-order spatial differencing for the convective fluxes. The computational domain extends to the farfield using Cartesian offbody grids that are used to resolve the rotor wake.

\footnotetext{
${ }^{a}$ Aerospace Engineer, Applied Modeling and Simulation Branch, M/S 258-2, Member AIAA

${ }^{b}$ Aerospace Engineer, Aeromechanics Branch, M/S 243-12, Member AHS

${ }^{\mathrm{c}}$ Computer Scientist, Computational Technologies Branch, M/S 258-5, Member AIAA
} 
The main objectives of this study are to validate the computational results for a UH-60A rotor, understand the interaction between flow structures in the rotor wake, and the vortex convection that is associated with forward flight. The detailed computational approach is presented in section II. A low-speed case with significant blade vortex interaction (BVI) was selected for analysis in this study. The experimental setup and PIV planes are briefly discussed in section III. In section IV, a brief description of the method used for computing vortex properties such as vortex core radius, position, and circulation is presented. Computed vortex properties are compared with the experiment. Vortex core properties from the CFD solution were determined using the same procedure used for the experimental data. ${ }^{1}$

In the present study, appropriate combination of spatial and temporal accuracy is based on convergence of the normal force coefficient. For vortex evolution, a functional using vortex core radius is used. These functionals provide an informal procedure to guide the selection of subiterations, time step, and spatial resolution for moving grid applications. The time step and the number of subiterations were selected to maintain the computational expense at an affordable level. Several aspects of the accuracy and sensitivities are described in section IV.

\section{Computational Approach}

Details of the various aspects of the OVERFLOW algorithms are discussed in Ref. 4. A brief description of the CAMRAD II comprehensive code, the fluid/structure loose coupling procedure, the UH-60A geometry and overset grids, and the OVERFLOW CFD code are described next.

\section{A. Comprehensive Code: CSD and Rotor Trim}

The rotorcraft CSD code used for this study is CAMRAD II ${ }^{7}$. The aerodynamics modules within CAMRAD II are based on lifting-line models utilizing airfoil tables, coupled with wake models. Within CAMRAD II, each blade is structurally modeled as a set of nonlinear beam elements. In addition to the structural dynamics modeling, CAMRAD II offers a trim capability. For the UH-60A simulations in this paper, a three degree-of-freedom trim was utilized, with the solidity-weighted thrust coefficient, pitching moment, and rolling moment specified as trim targets within CAMRAD II. In turn, CAMRAD II provides the collective pitch, longitudinal cyclic, and lateral cyclic pitch angles. The details of this comprehensive code and coupling strategies are described in Ref. 7 as well as in Refs. 2-3.

\section{B. Fluid/Structure Interaction: Loose Coupling}

For steady flight conditions, a loose coupling between CFD and CSD is employed, since the interaction between the structure and aerodynamic response is periodic and not required at every flow solver time step ${ }^{7}$. The goal of the loose coupling approach is to correct the low-order aerodynamics of the comprehensive code with the high fidelity Navier-Stokes CFD code. Coupling is typically invoked once every revolution, or some fraction of a revolution based on the number of rotor blades. At each coupling step, CFD rotor loads are provided to CAMRAD II; CAMRAD II uses these CFD loads to make a correction to its own lifting-line aerodynamics model to re-trim the rotor. CAMRAD II then provides a new rotor-blade deflection file to the CFD code. When this loosely coupled process is converged, the CFD airloads have replaced those of the comprehensive analysis. Reference 2 provides additional details on the coupling procedure.

\section{Rotor Geometry/CFD Grid}

\begin{tabular}{|l|l|}
\hline Number of Blades & 4 \\
\hline Radius, ft & 26.83 \\
\hline Nominal Chord, in & 20.9 \\
\hline Blade Tip Sweep, deg aft & 20 \\
\hline Geometric Solidity & 0.0826 \\
\hline Airfoil Section Designation & SC1095R/SC1095R8 \\
\hline Thickness, \%chord & 9.5 \\
\hline $100 \%$ RPM & 258 \\
\hline Root Cutout & $0.13 \mathrm{R}$ \\
\hline
\end{tabular}

Table 1. UH-60A rotor parameters.

The UH-60A rotor blade has a nonlinear twist with a swept tip. The rotor characteristics are shown in Table 1. Figure 1 shows the blade planform reproduced from Refs. 1 and 6 . The tab bend radius is 0.8 inches from the 
trailing edge. The blade trim tab is deflected non-uniformly from 0.3 degree to 3.3 degrees for the four blades. However, in the computation, an average uniform deflection of 1.8 degrees upward was used for all the blades uniformly.

The overset grid system used in the present simulations was generated using Chimera Grid Tools (CGT) ${ }^{8}$ software. The CGT contains a very efficient and modular grid scripting library used for grid manipulation, generation, reorganization, overset hole cutting surfaces, and generation of OVERFLOW input files. This scripting procedure produces high quality surface grids and subsequent volume grids with a set of input parameters. These input parameters allow one to quickly and automatically modify the grid system for the existing geometry.

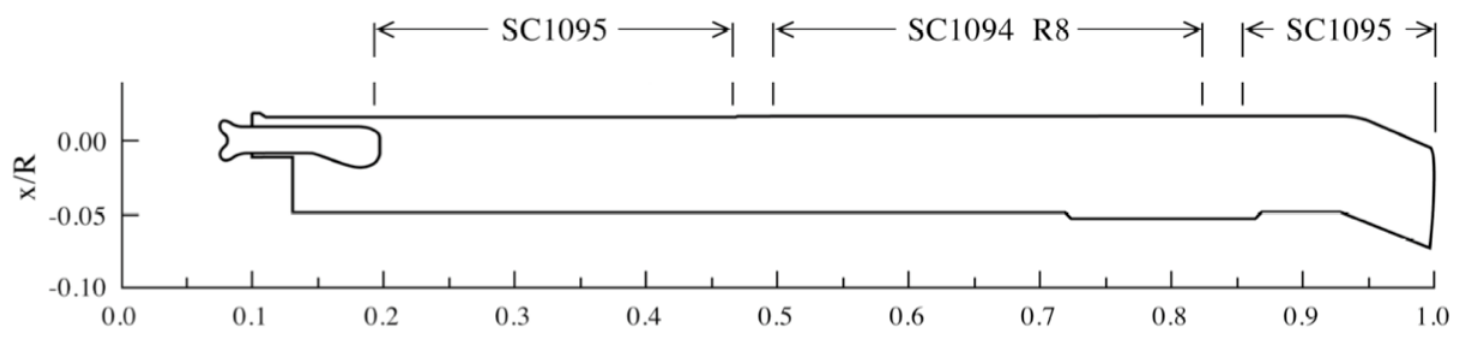

Figure 1. Schematic of blade planform. ${ }^{1,6}$

The O-grid system used in the present simulations is shown in Fig. 2. The blade tip geometry is faithfully represented in the surface grid, including all sharp edges. The overset grid for each rotor blade consists of three separate grids: the main rotor-blade body, a cap grid at the outboard tip, and a cap grid at the inboard root. The main rotor-blade body uses an O-mesh topology that maintains good surface resolution. The viscous spacing provides an average $\mathrm{y}^{+}$of approximately 1.0 or less. "Near-body" grids refer to the curvilinear overset grids attached to the rotor. These are imbedded into Cartesian "off-body" grids that resolve the rotor wake region and extend the computational domain to the farfield. These off-body Cartesian grids are automatically generated within OVERFLOW according to user specified input parameters. Moreover, the off-body Cartesian grids are generated at various levels of resolution starting from "Level 1" (L1) in the rotor-wake region, to successively coarser grid levels (L2, L3, L4...etc.) to rapidly and efficiently extend the grid system to the far field. For this study, the L1 vortex-wake grid spacing is constant and several grids were generated with spacing varying from $0.05 \mathrm{c}_{\text {tip }}$ to $0.14 \mathrm{c}_{\text {tip }}$. The $\mathrm{c}_{\text {tip }}$ is the rotor tip chord length. The farfield boundaries are twelve rotor radii from the rotor center. Detailed grid statistics are shown in Table 2 in section IV.
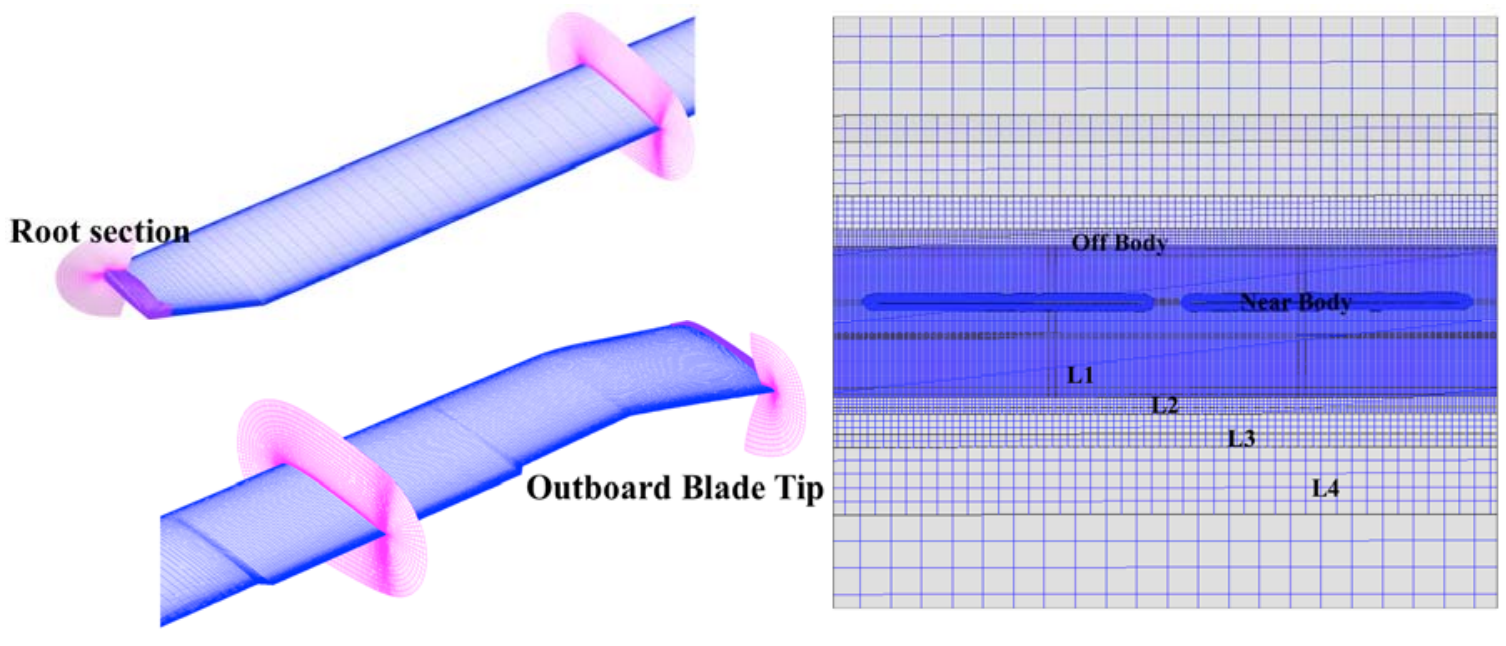

Figure 2. UH-60A blade grid with background Cartesian mesh.

\section{Flow-Solver Algorithm}

OVERFLOW is a finite-difference, overset grid, RANS CFD code. User-supplied, body-fitted structured grids are employed near solid surfaces, with automatically generated background Cartesian grids filling the remainder of 
the computational domain. Higher-order spatial differences for convective fluxes with $5^{\text {th }}$ order accuracy on uniform Cartesian grids are available. The code has several upwind flux schemes to improve the numerical accuracy for high-speed applications as well as for vortex dominated flows. The results presented here were obtained using one of the $\mathrm{HLL}^{9}$ family of upwind approximate Riemann flux algorithms, namely, the contact-preserving HLLC ${ }^{10}$ variant, with nominally 5 th order WENO reconstruction for the inviscid fluxes. To advance the solution in time, an implicit, second-order backward difference scheme is used in which the nonlinear system of equations is linearized at each time step. In this study, the resulting system of linear equations is solved using symmetric successive overrelaxation $(\mathrm{SSOR})^{11}$, which eliminates factorization errors at the expense of more computational work and memory per time step. Within OVERFLOW, several time-stepping schemes are available, including dual-time schemes. This study used a Newton iteration scheme. For this simulation, OVERFLOW used anywhere from 10 to 40 subiterations at each time step. A number of turbulence models are available in OVERFLOW. Here, the standard one-equation model of Spalart-Allmaras ${ }^{12}$ and two-equation $k-\omega \mathrm{SST}^{13}$ together with Detached Eddy Simulation $(D E S)^{14}$ length scale models are utilized.

\section{Experimental Setup}

A brief description of the PIV installation is reproduced here from Refs. 1 and 6 . The primary goal of the PIV installation was to provide rotor wake characteristics over the outer $50 \%$ of the UH-60A rotor blade radius. Figure 3 shows the location of the PIV system components in the wind tunnel. During the test, flow field velocity components were measured in a stationary cross-flow plane located at approximately 90 deg rotor azimuth. This cross-flow plane (Region Of Interest (ROI)) was approximately 3.5 -ft. high by 14 -ft. wide. The PIV ROI is shown in Fig. 3.

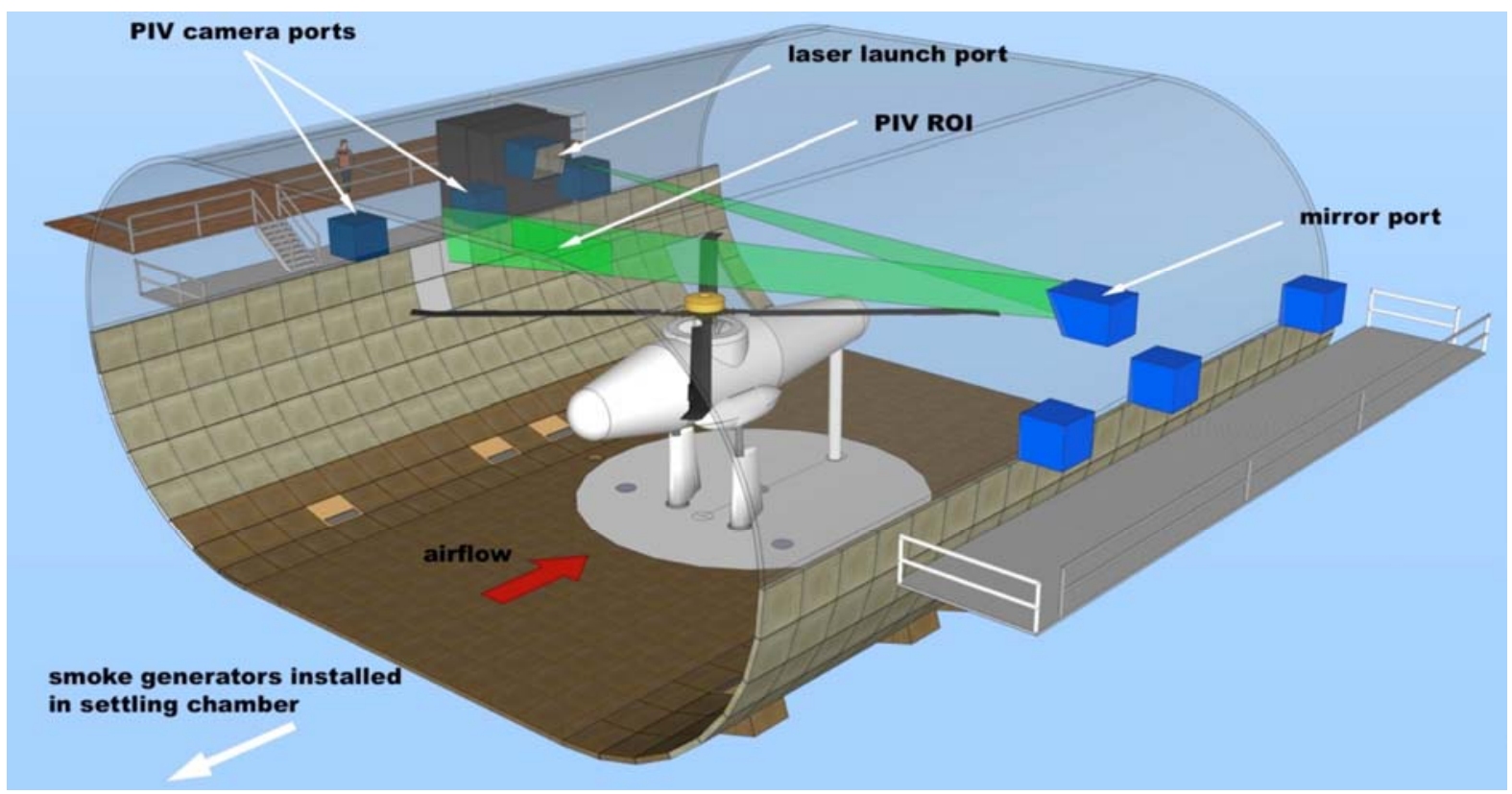

Figure 3. PIV system in the 40 by 80 -ft Wind Tunnel for UH-60 A Airloads test ${ }^{1,6}$. 


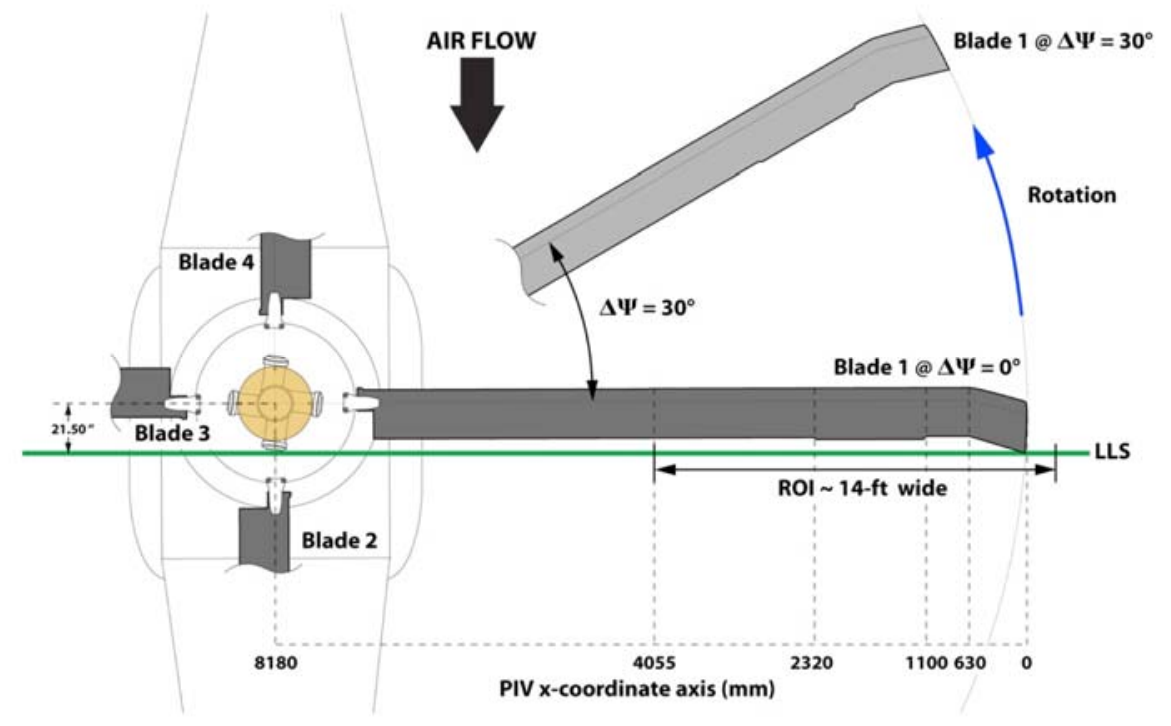

Figure 4. Blade orientation with respect to the Laser Light Sheet (LLS) ${ }^{1,6}$.

The laser and the camera systems were synchronized with the rotor. The measurements were acquired for different blade azimuths relative to the Laser Light Sheet (LLS). The angle between the LLS and the blades are referred to as delayed azimuth $\Delta \psi_{n=1,2,3,4}$ for example, the angle between the LLS and the primary blade, Blade 1 (B1) is called the delayed azimuth or $\Delta \psi_{1}$. The zero delayed azimuth $\left(\Delta \psi_{1}=0\right)$ is when the tip trailing edge of B1 intersects the LLS. Figure 4 shows the schematic of the blade positions relative to the LLS. One hundred PIV frames were acquired for each delayed azimuth.

\section{Results}

References 1 and 6 provide a complete list of test conditions for which PIV data were acquired. For this paper, test condition Run 73 is selected. The Run 73 is a low-speed flow with significant Blade Vortex Interaction (BVI). The advance ratio is $\mu=\frac{M_{\infty}}{M_{t p}}=0.15$, the freestream Mach number is $\mathrm{M}_{\infty}=0.0975$, and the tip Mach number is $\mathrm{M}_{\text {tip }}=$ 0.65. Measured airloads, structural loads, control positions, and rotor forces and moments are available for comparison with analyses.

Figure 5 shows a view of the computed vortex wake. The vortex cores are rendered using iso-surfaces of the Qcriterion $^{2-3}$. The vortex evolution shows the growth structure, wandering, turbulence merging, and somewhat complex merging with the shear layer and with tip vortices from other blades. The shear layer leaving the blade and the vortex evolution are interdependent. One purpose of this paper is to assess the prediction capability of the solver for such complex flows.

A limited verification procedure was performed to assess solution sensitivity to spatial resolution, temporal resolution including the number of subiterations used at each time step, and the CFD/CSD loose coupling frequency. Previously, slightly different verifications were performed for similar computations ${ }^{2-3}$. A series of runs was performed to determine an optimum choice of parameters for computation. Computations were performed for spatial, temporal, and subiteration convergence with the following combinations:

1: Subiteration variations $-\left\{h_{3},(\Delta t)_{2}, S_{i=1,4}\right\}: S_{i}=10,18,25,40$

2: Time step variations - $\left\{h_{3},(\Delta t)_{i=1,4}, S_{2}\right\}:(\Delta t)_{i}=0.5,0.25,0.10,0.05 \mathrm{deg}=323,161,64,32 \mu \mathrm{s}$

3: Spatial variations - $\quad\left\{h_{i=1,4},(\Delta t)_{2}, S_{2}\right\}: h_{i}=0.032,0.0026,0.0023,0.0014$

Here, $\Delta t$ is equivalent to an incremental azimuthal advance $\Delta \psi$ in degrees per physical time step (shown as micro second), $S$ is the number of subiterations used, $h$ is the grid spacing. This parameter set provides reasonable 
information for making choices for numerics in practical simulations with some convergence measure. A function or a functional can be used to assess the sensitivity of the results with respect to this convergence measure. For this validation, convergence measures based on two functionals were used: (1) airloads and (2) vortex core size.

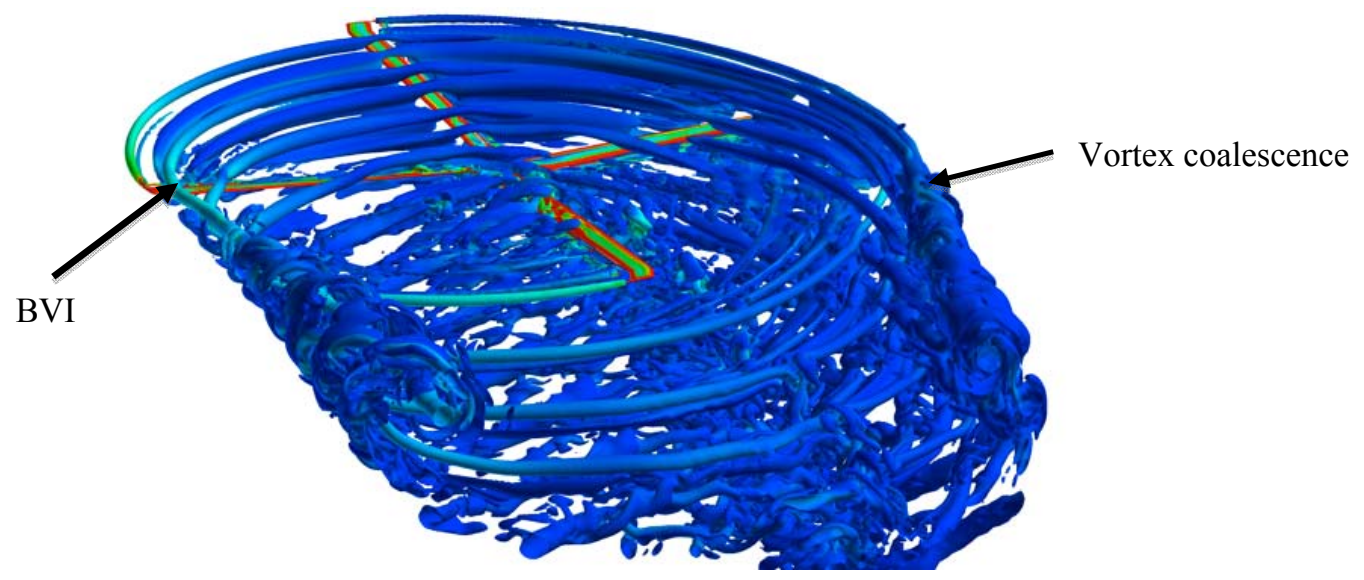

Figure 5. View of vortices visualized with the Q-criterion. Run $73 \mathrm{M}_{\text {tip }}=0.65, \mu=0.15$.

For airloads, the quantity of interest is the function that gives blade sectional normal forces, $M^{2} C_{n}$ :

$$
F(\psi, r)=M^{2} C_{n}
$$

For error estimation, the finest level of resolution for grid and time, or largest number of subiterations was used as a reference to compute difference in the solutions.

For vortex evolution, the following functional of core radius $(r c)$ was used.

$$
F(\psi)=r c(\Delta \psi)
$$

\section{A. Spatial Sensitivity Analysis}

\begin{tabular}{|l|l|l|l|l|l|l|l|}
\hline Grid & $\begin{array}{l}\text { Total } \\
\text { Nearbody } \\
\text { points in } \\
\text { millions }\end{array}$ & $\begin{array}{l}\text { Total } \\
\text { surface } \\
\text { points in } \\
\text { millions }\end{array}$ & $\begin{array}{l}\text { Total points } \\
\text { in millions }\end{array}$ & $\begin{array}{l}\text { Initial } \\
\text { Normal } \\
\text { spacing }\end{array}$ & $\begin{array}{l}\text { L1 } \\
\text { Spacing }\end{array}$ & $\begin{array}{l}\text { Total } \\
\text { grids }\end{array}$ & $\begin{array}{l}\text { Grid extent } \\
\text { in Radius }\end{array}$ \\
\hline $\begin{array}{l}\text { Grid 1: } \\
\text { Coarse-1 }\end{array}$ & 18.2 & 0.28 & 31.9 & $1.5 \mathrm{e}-04$ & 0.14 Ctip & 52 & $12 \mathrm{R}$ \\
\hline $\begin{array}{l}\text { Grid 2: } \\
\text { Coarse-2 }\end{array}$ & 18.2 & 0.28 & 58.6 & $1.5 \mathrm{e}-04$ & 0.10 Ctip & 62 & $12 \mathrm{R}$ \\
\hline $\begin{array}{l}\text { Grid 3: } \\
\text { Medium }\end{array}$ & 37.1 & 0.57 & 77.5 & $1.5 \mathrm{e}-04$ & 0.10 Ctip & 62 & $12 \mathrm{R}$ \\
\hline $\begin{array}{l}\text { Grid 4: } \\
\text { Fine }\end{array}$ & 39.4 & 0.57 & 328 & $1.5 \mathrm{e}-04$ & 0.05 Ctip & 124 & $12 \mathrm{R}$ \\
\hline Adaption & 37.1 & 0.57 & 788 & $1.5 \mathrm{e}-04$ & 0.10 Ctip & 1360 & $12 \mathrm{R}$ \\
\hline
\end{tabular}

Table 2. Grid statistics and the computational domain extension.

For grid sensitivity, four different meshes were generated. Table 2 shows the details of these grids. Two coarse grids used the same surface resolution. Only the L1 grid spacing is varied for generating two coarse grids. For the medium and fine grids, the surface mesh resolution is double that of the coarse meshes. The medium grid uses $0.1 c_{\text {tip }}$ grid and the fine level uses $0.05 \mathrm{c}_{\text {tip }}$ in the L1 spacing. Spatial errors are represented in a global measure of average

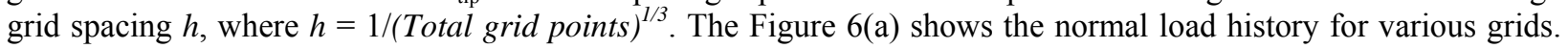


The Fig. 6(b) shows the percent error estimate in a $\log -\log$ plot. From the $M^{2} C_{n}$ history, the medium and fine mesh shows minimal changes. Based on this, the medium mesh is used for the validation.

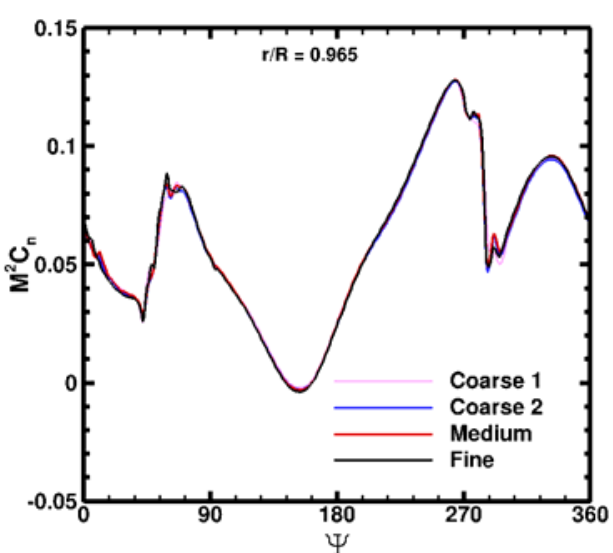

(a) Normal Force function variation.

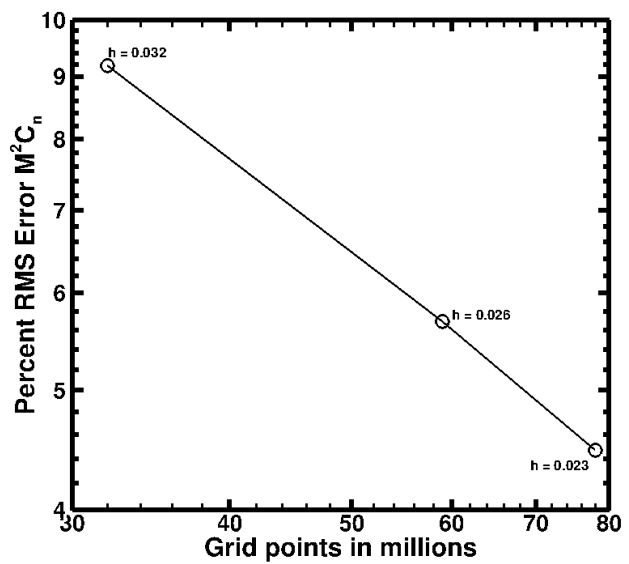

(b) Spatial error estimate.

Figure 6. Spatial sensitivity analysis with various grids, $\mathrm{M}_{\mathrm{tip}}=0.65, \mu=0.15$

\section{B. Subiterations Sensitivity Analysis}

The effect of number of subiterations required for time accuracy was examined. Figure 7(a) shows the normal force coefficient history and Fig. 7(b) shows the corresponding error based on the highest subiteration. Based on previous experience (Refs. 2-3), a fixed time step of $0.25 \mathrm{deg}$ was used to achieve time accurate results. Comparison with experimental airloads data is shown in Fig. 7(a) for a blade section at $96.5 \%$ radial station. The calculations captured the measured waveform, however, there are marked differences in magnitude on the retreating side. The BVI events are captured well at both advancing and retreating sides.

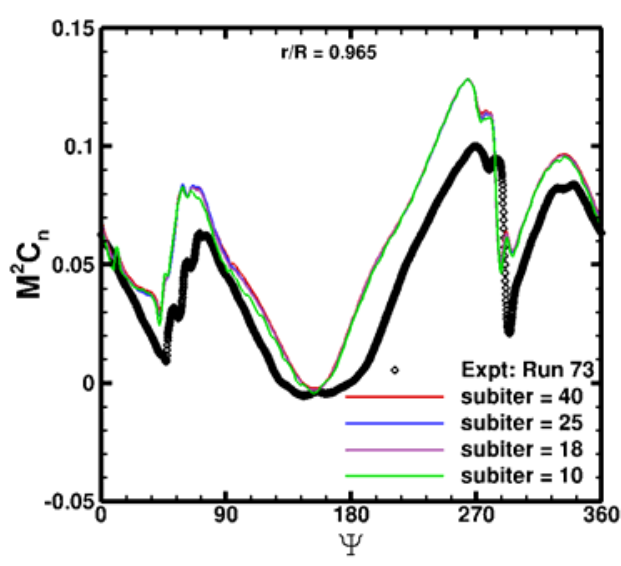

(a) Normal Force function variation.

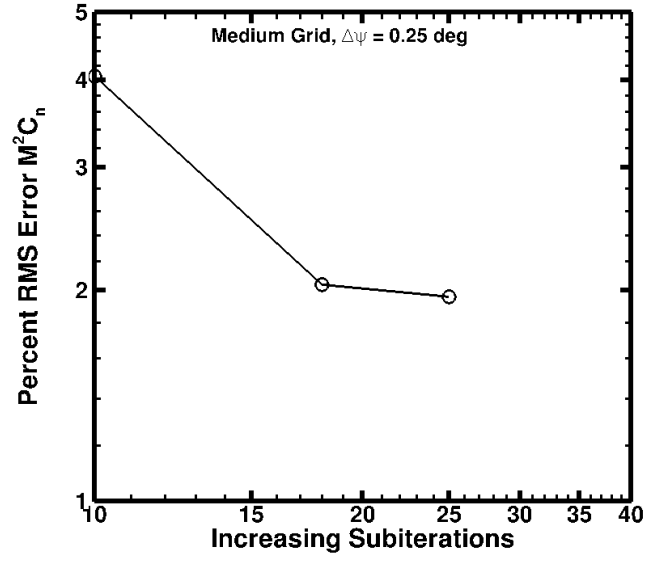

(b) Subiteration error estimate.

Figure 7. Subiteration sensitivity analysis, $\mathrm{M}_{\mathrm{tip}}=0.65, \mu=0.15$.

Examining the function history and error relative to the highest number of subiterations, acceptable trade-off of simulation time and error is achieved at 18 subiterations.

\section{Time Step Sensitivity Analysis}

Based on 18 subiterations, the time step sensitivity was studied using time steps of 0.5 degree to 0.05 degree. Careful choice of space-time resolution is important for the helicopter problem, especially for the low advance ratio case where strong BVI complicates the vortex evolution. For grid resolution and time step requirements following 
an example shown in Ref. 15, space-time requirement for the UH-60 simulation is briefly presented in this section. The CFL number based on physical time step is defined as:

$C F L=\frac{u \Delta t}{h}=\frac{(\mu \Omega R) \Delta t}{h}$, where $h$ is the global spatial resolution defined below,

$u$ is assumed to be convection speed of the vortex, is $\mu$ is the advance ratio.

Typical vortex core diameter at early wake age is $10 \%$ of the tip chord for rotor in hover. For the UH- $60 \mathrm{~A}$ rotor blade, the core is approximately equal to $R / 150$ and if there are 10 points across the core, the spatial resolution requirement is approximately

$h=\frac{R}{1500}$. This leads to a very big mesh size on the order of billion cells.

For accurate convection of vortex, a CFL on the order of one is recommended. Based on this,

$\frac{\Delta t}{T}=\frac{h / R}{2 \pi \mu}$

$\mathrm{T}$ is the total time in a revolution, $\Omega$ is the angular velocity. Typical $\mu$ varies from 0.1 to 0.35 . This would lead to time steps per revolution of $O\left(10^{3}\right)$ (Eq. 3). For trim and aeroelasticity, one needs to run several revolutions. So local grid refinement using grid adaption with space-time convergence is the preferred method to solve this problem. In this paper, time step sensitivity is studied only for fixed spatial resolution. Figure 8 represents the time step sensitivity that does not show convergence. However, the load (Fig.8(a)) seems to be insensitive to these three timesteps of 0.1 to 0.5 degree. Error varies from $1 \%$ to $2.4 \%$.

Based on the sensitivity analysis above, a time step equivalent of 0.25 degree, 18 subiterations, and medium as well as fine grid (Table 2) were used for the vortex evolution study.

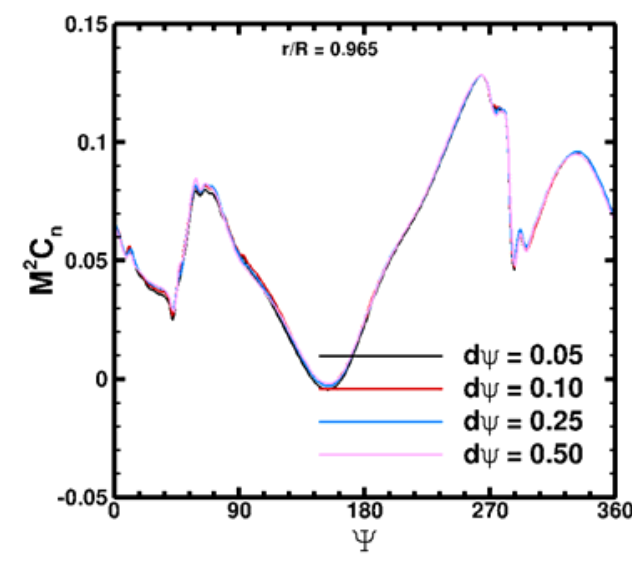

(a) Normal Force function variation.

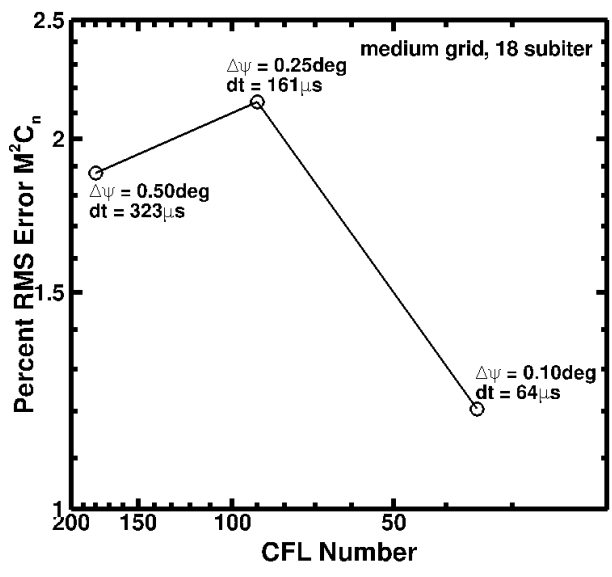

(b) Temporal error estimate.

Figure 8. Time step sensitivity analysis, $\mathrm{M}_{\mathrm{tip}}=0.65, \mu=0.15$

\section{Loose Coupling Sensitivity}

A loose coupling between CFD and CSD is done in a periodic manner. The goal of the loose coupling approach is to correct the low-order aerodynamics of the comprehensive code with the high fidelity Navier-Stokes CFD code. Coupling is typically invoked once every revolution, or some fraction of a revolution based on the number of rotor blades. Figure 9 shows the sensitivity of the normal force coefficient to the coupling steps, which shows relative insensitiveness of the coupling steps. Figure 9(a) shows the sectional load at a radial station of 0.965R, while Fig. 9(b) shows the radial loads for all the coupling steps. For this study, coupling at quarter revolution is used. 


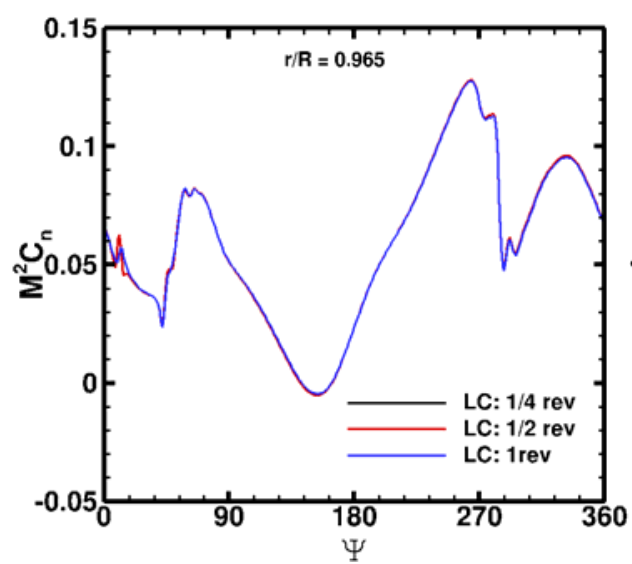

(a) Normal Force variation.

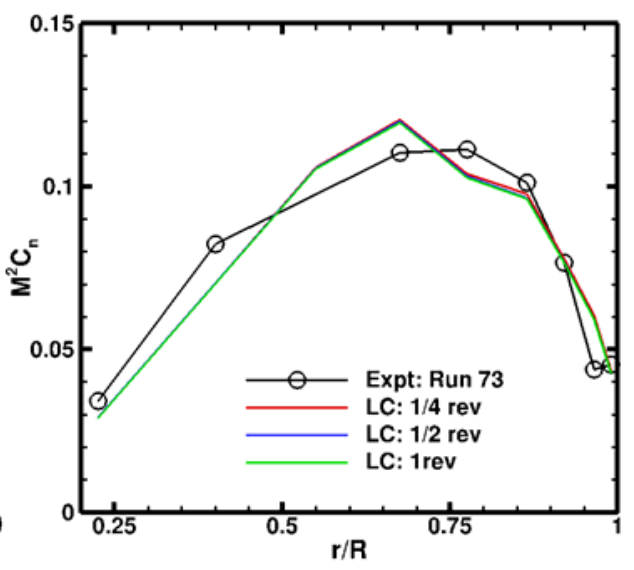

(b) Radial load for various coupling frequency

Figure 9. Coupling sensitivity of $\mathrm{CFD} / \mathrm{CSD}, \mathrm{M}_{\mathrm{tip}}=0.65, \mu=0.15$.

\section{E. Turbulence Model Sensitivity}

Two turbulence models were tested in this simulation, Spalart-Allmaras (SA) ${ }^{12,14}$ and $k-\omega \mathrm{SST}^{13}$ each with Detached Eddy Simulation (DES) length scale. In Fig. 10(a), both turbulence models show similar agreement with the experimental airloads data. The reason for the differences between measurement and prediction is not obvious at this point. The choice of turbulence model alone does not explain these differences. The load fluctuations at first and fourth quadrants that are related to BVI events are captured by the analysis. The loose coupling convergence for different coupling cycles with the SA model is shown Fig. 10(b). Over 20 loose coupling cycles were required to achieve convergence. Similar convergence was also achieved with SST model.

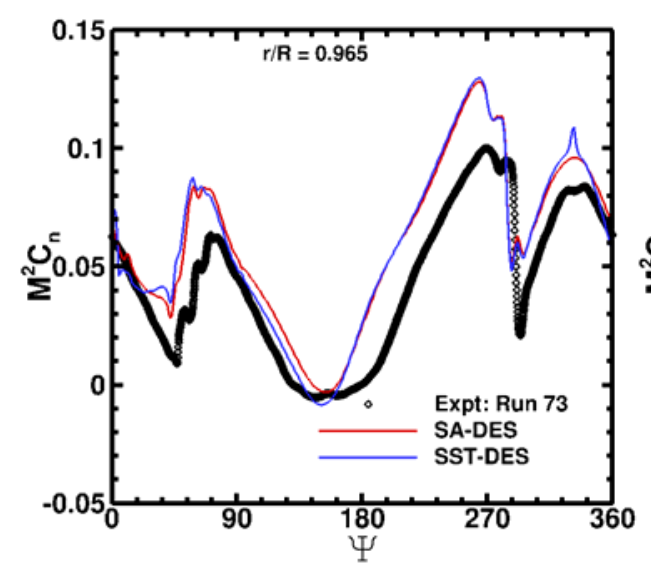

(a) Normal Force compared with Experiment: Run 73.

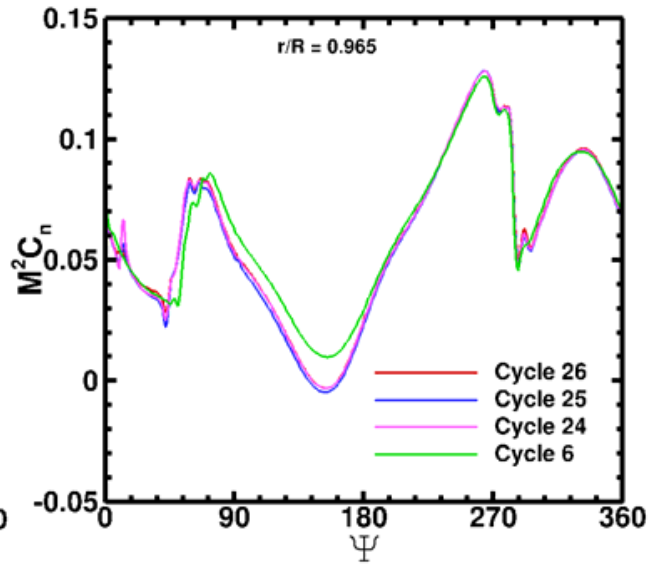

(b) Convergence of Normal Force for SA-DES model.

Figure 10. Turbulence model variation, $\mathrm{M}_{\mathrm{tip}}=0.65, \mu=0.15$.

\section{F. Comparison of Measured and Computed Wake Characteristics}

As demonstrated in Refs. 16-18 and in this paper, grid spacing on and near the rotor blade is critical if the objective is to compute flow features in the near wake. Likewise, measurements in the near wake must have sufficient spatial resolution to resolve the features of interest (Ref. 1). Assuming that the computation and experiment have been executed with sufficient spatial resolution, comparing computed and measured flow fields of a rotor in forward flight presents several challenges. First, the approach for extracting vortex properties becomes complicated since the tip vortex filaments are usually not orthogonal to the measurement plane and depending on the test condition, the filaments from multiple blades may be in close proximity to each other and to the trailed sheets of the blades. When processing a measured velocity field, Refs. 18-20 developed approaches to rotate the velocity field into a plane orthogonal to the vortex filament of interest and then extract the vortex core size, strength, and location 
using an area fit of the measured field to a vortex model. The cross-section of the filament is assumed to be circular in the vortex models used in Refs. 19-20. Second, unlike a CFD solution, an instantaneous measured velocity field represents a snapshot of an unsteady flow environment that varies from one rotor revolution to another, hence typically a hundred or more velocity fields are needed to provide statistically meaningful results. Various approaches for averaging the instantaneous fields to account for vortex aperiodicity are described in the literature (Refs. 19-20 for example). A question arises, then, of whether to compare the CFD solution with instantaneous measured vector fields, a conditionally averaged subset of the measured field, or an ensemble averaged field. The answer depends on the level of validation desired by the analyst.

The present study used the following approach for comparing computed and measured velocity fields. First, the instantaneous CFD solution was compared with the experimental ensemble averaged velocity fields on the same PIV plane (Figs. 11-15). These comparisons can quickly identify whether gross flow field features (for example, number of vortices, rotation direction of vortices, relative position of vortices, shear layer) are captured by the computation. Next, for comparing individual vortex properties, the area fit procedure (Refs. 19-20) used to extract tip vortex properties from the measurements was also used to extract properties from the CFD velocity field.

Computational wake results are compared with data acquired in the PIV measurement plane in Figs. 11-15 (view looking upstream). For each delayed azimuth, 3 to 5 vortices and shear layers are visible in the plane. The measurements represent ensemble averaged out-of-plane vorticity components, whereas CFD results are shown for only one time step. A mask (defined by the black outlines in Figs. 11(a)-15(a) and 11(c)-15(c)) was used when processing the PIV images to eliminate regions not illuminated by the laser sheet. Vortices from four blades are identified as Blade 1 (B1), Blade 2 (B2), Blade 3 (B3), Blade 4 (B4) respectively from which the vortex originated. Note that B4 is $90 \mathrm{deg}$ ahead of B1, B3 is $180 \mathrm{deg}$ ahead of B1, and B2 is 270 deg ahead of B1. This orientation is clear if one refers back to Fig. 4. A fourth vortex, identified as V, is generated by the roll-up of a portion of the shed wake between the outboard edge of the tab and the beginning of the tip sweep. A vortex at each trim tab end is visible in the experiment but the computation shows a weak vortex at the outboard end of the tab and a very weak or no vortex at the inboard end of the tab. Reference 1 indicated that the vortex from the outboard edge of the tab has the opposite sign of the main tip vortex. Figures 11 and 12 show comparisons for delayed azimuth of $\Delta \psi_{1}=5^{\circ}$ and

$\Delta \psi_{1}=60^{\circ}$, respectively, for Blade 1. In Figs. 11-15, (a) is the experimental vorticity field, (b) is the corresponding CFD vorticity field, and (c) is particle traces from the CFD simulation overlayed on the grey-scaled experimental vorticity field. These combined experiment and CFD plots help to qualitatively compare experiment and computation. In the computation, the particles are released from the blade tip and around the trailing edge (up to the beginning of the trim tab) of each blade. Particles released are colored by individual blade to distinguish vortices from different blades as they pass through the PIV plane, for example, green represents Blade 1, blue represents Blade 4, cyan represents Blade 3, and red represents Blade 2. The CFD simulation captures the main features of the measured flowfield. In addition CFD simulation shows continuity between the shear layer and the corresponding tip vortex for each blade. Figures 13-15 show comparison for a delayed azimuth 5 deg for Blade 2, Blade 3, and Blade 4 while Blade 1 at 5 deg is shown in Fig. 11. Blade to blade differences can be assessed from Figs. 11, 13-15. The four blades are not identical geometrically and structurally, leading to differences in tracking and blade deformation for a given rotor azimuth. The experimental results therefore show small differences in flow field features. The CFD results however show very minor differences as all the blades are modeled to be geometrically and structurally identical. 


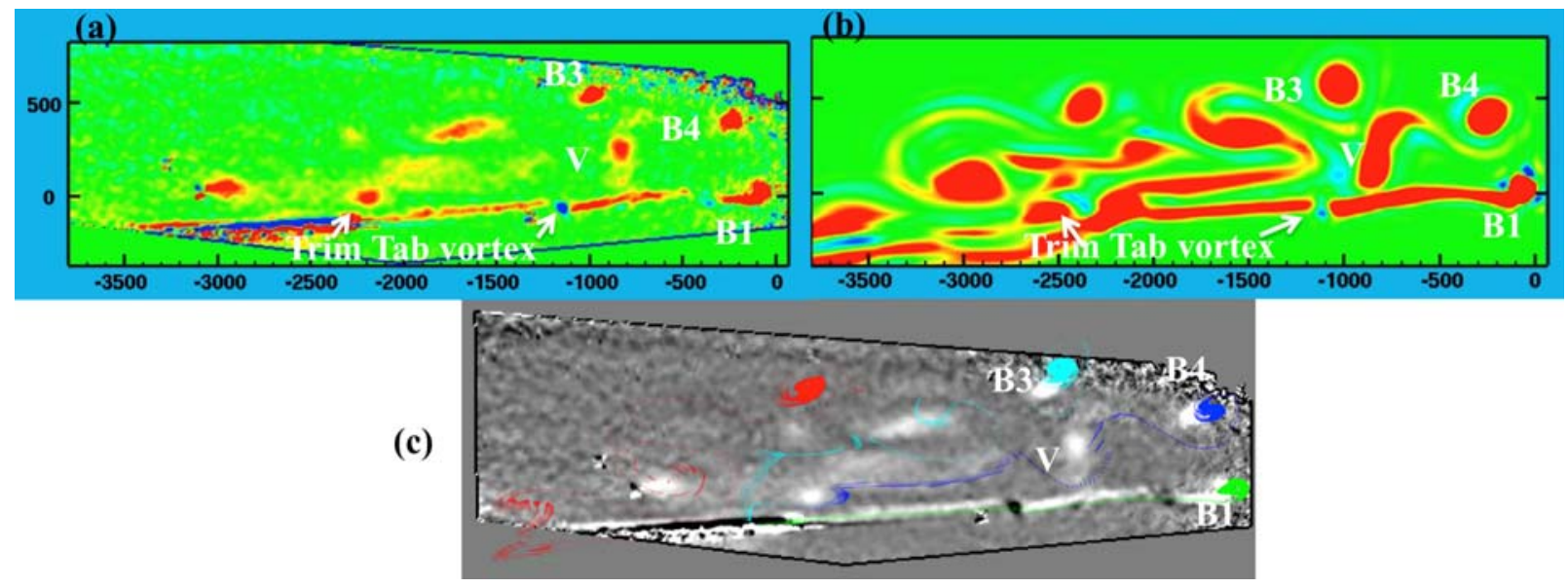

Figure 11. Vorticity fields generated by Blade 1 at $\Delta \psi_{1}=5^{\circ}$. (a). Expt: Run 73, (b). Computed, (c). Computed particle trace overlays on grey-scale experimental vorticity field as shown in (a).

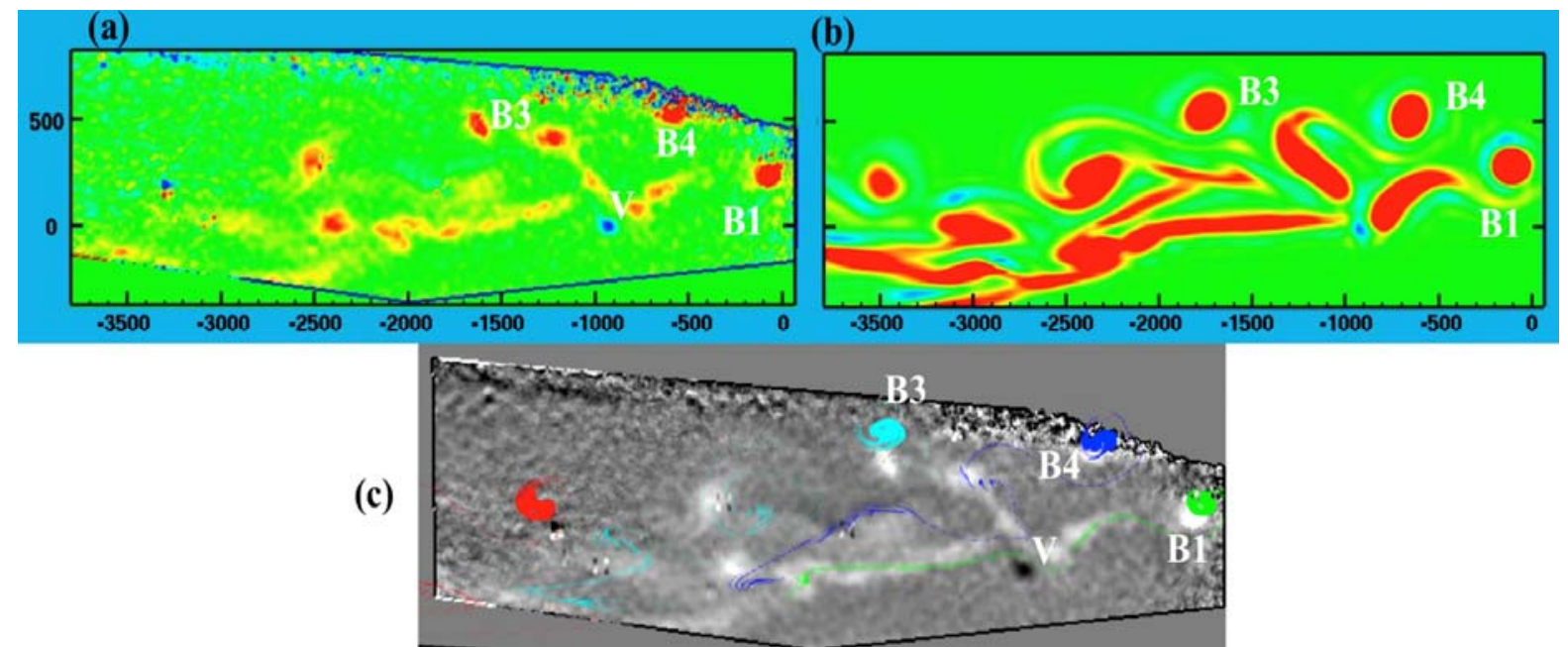

Figure 12. Vorticity fields generated by Blade 1 at $\Delta \psi_{1}=60^{\circ}$. (a). Expt: Run 73, (b). Computed, (c). Computed particle trace overlays on grey-scale experimental vorticity field as shown in (a). 


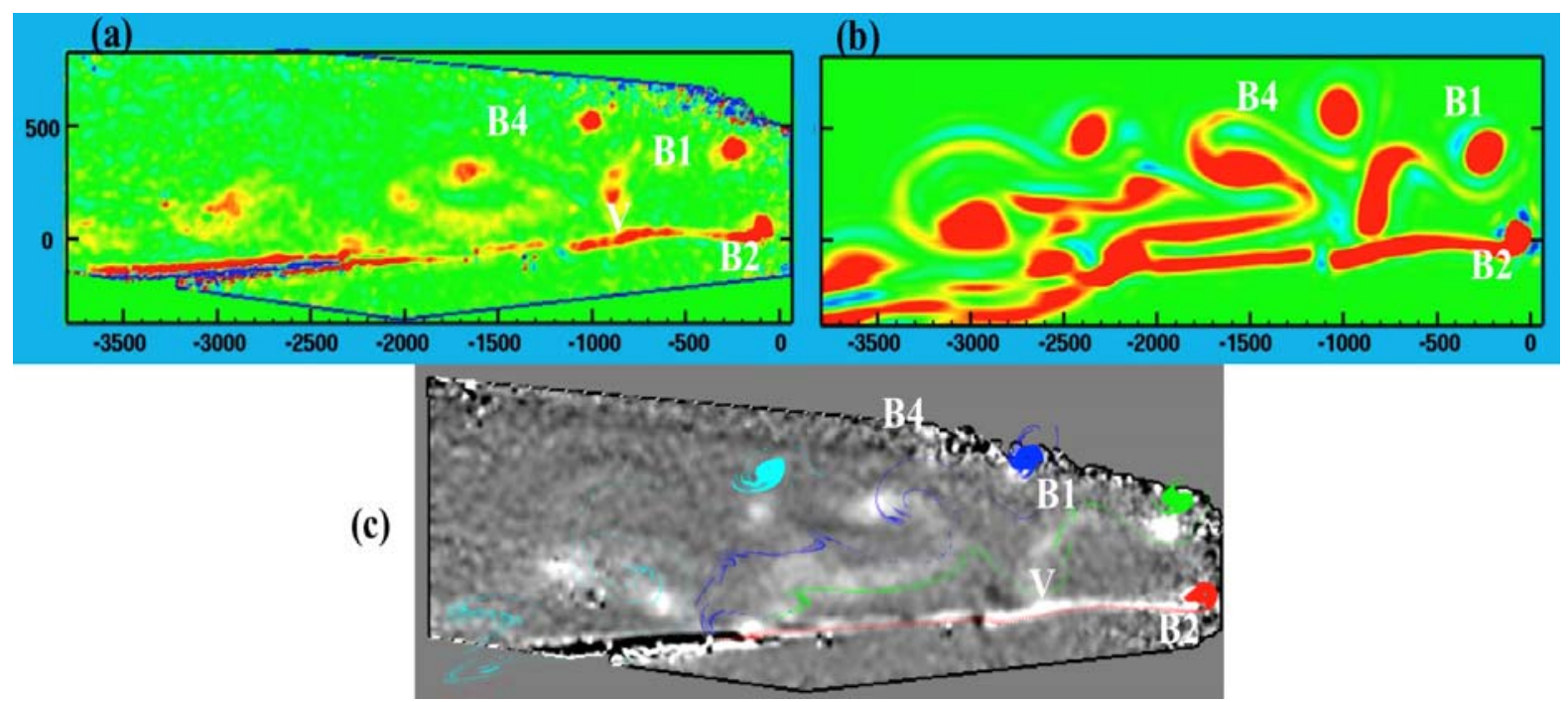

Figure 13. Vorticity fields generated by Blade 2 at $\Delta \psi_{2}=5^{\circ}$. (a). Expt: Run 73, (b). Computed, (c). Computed particle trace overlays on grey-scale experimental vorticity field as shown in (a).

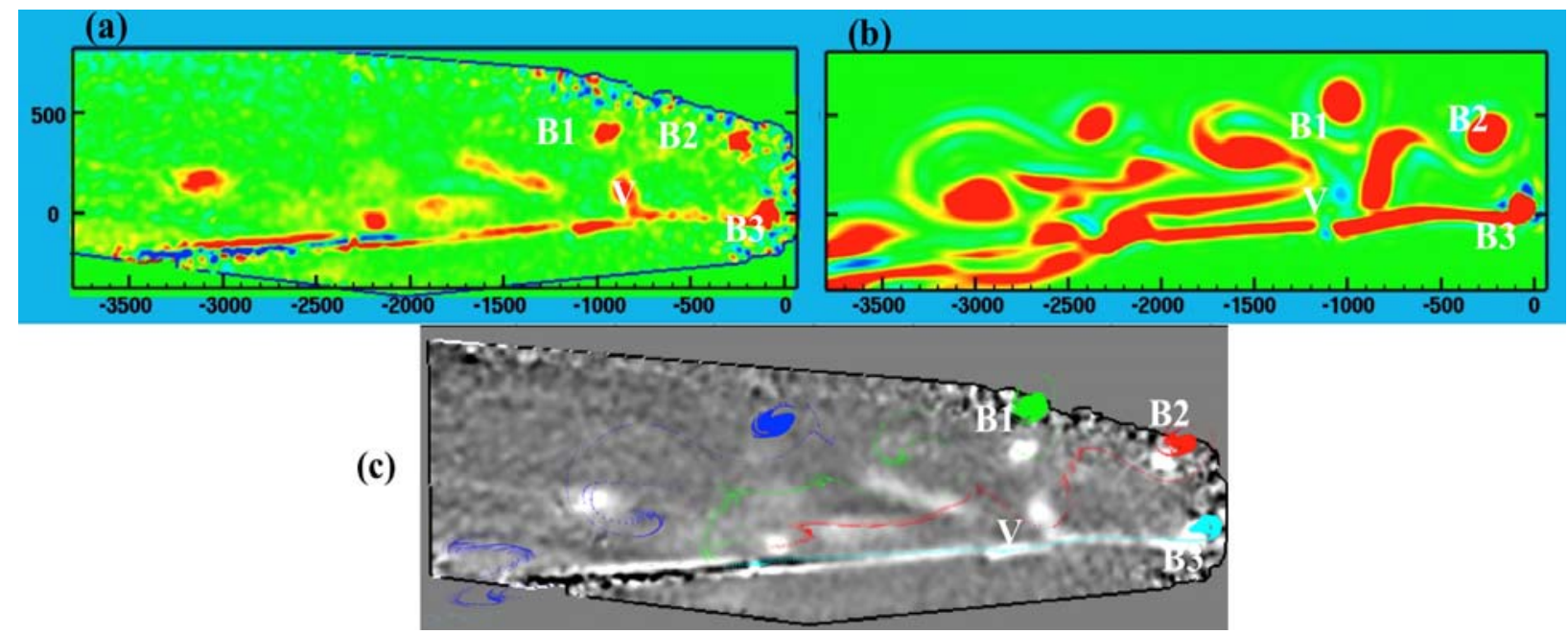

Figure 14. Vorticity fields generated by Blade 3 at $\Delta \psi_{3}=5^{\circ}$. (a). Expt: Run 73, (b). Computed, (c). Computed particle trace overlays on grey-scale experimental vorticity field as shown in (a). 


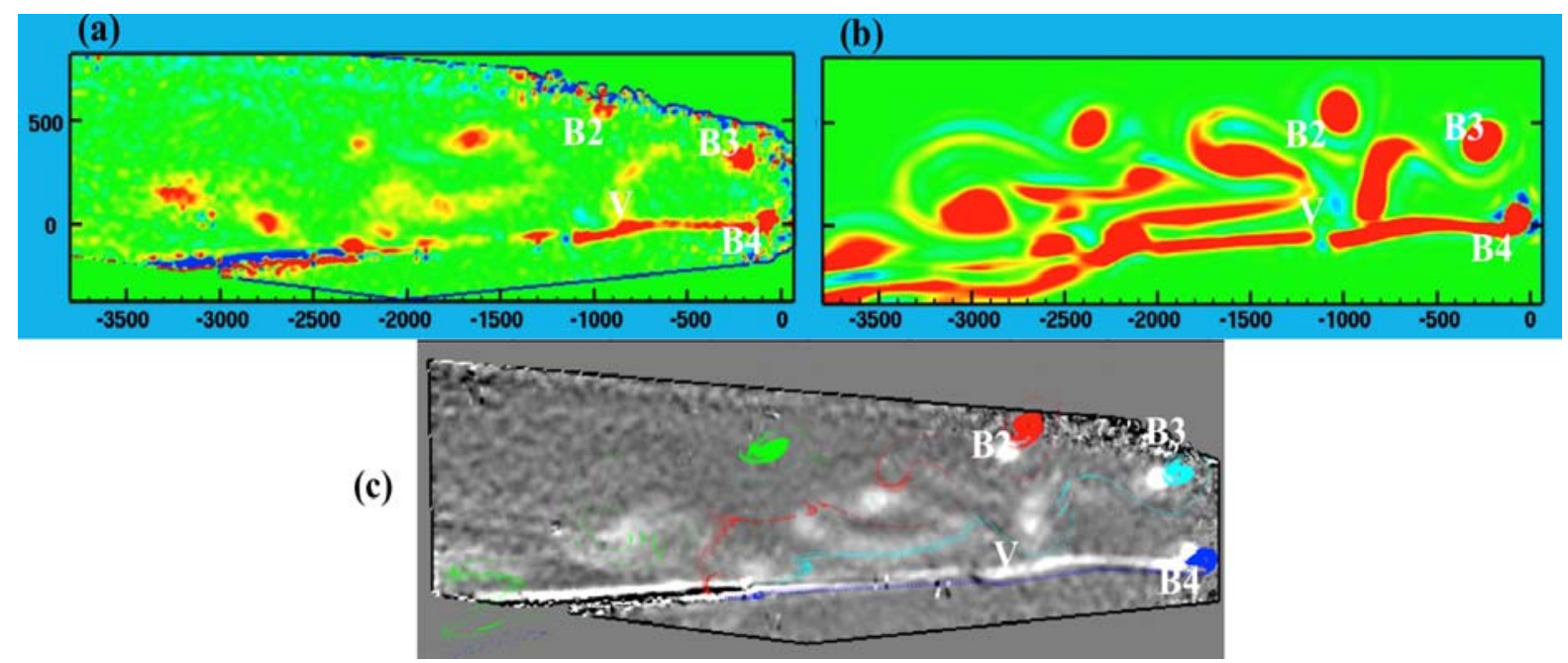

Figure 15. Vorticity fields generated by Blade 4 at $\Delta \psi_{4}=5^{\circ}$. (a). Expt: Run 73, (b). Computed, (c). Computed particle trace overlays on grey-scale experimental vorticity field as shown in (a).

\section{G. Comparison of Vortex Core Properties}

In order to compare computed and measured vortex characteristics, a single instantaneous CFD velocity field was processed using the same procedure used for the measurements, as described in Ref. 1. The procedure is briefly summarized here.

Using the measured ensemble averaged velocity field (or a single CFD velocity field), a vortex of interest was identified and the approximate vortex center (based on maximum vorticity) was noted. A square subregion about the center was then extracted as input to the planar fit analysis described in Ref. 1. The size of the subregion was chosen to ensure that the planar fit analysis, which estimates the core properties, has enough data to accurately determine the circulation contained within the vortex. For the experimental data, an approximately 150 - by 150 -mm subregion was extracted from each of the 100 instantaneous velocity fields. For the single CFD field, an approximately 200- by 200-mm subregion was used since the vortices by inspection of Figs. 11-15 are more diffused than the measured vortices. The 100 measured subregions were individually analyzed using a planar fit analysis to extract vortex properties. The planar fit analysis uses a least-squares fit of the subregion to an assumed vortex model - a Lamb model was used in Ref. 1 and in this study. Reference 1 provides additional details of the processing method.

A number of vortices from the CFD field were chosen for comparison with the experimental data. Table 3 replicates some of the measurements provided in Table 2 of Ref. 1 for a range of $\Delta \psi$. In Table 3, xc, yc are the vortex position, $r c$ is the vortex core radius, and $\Gamma$ is the vortex circulation. Vortex properties obtained from a corresponding single CFD velocity field are also included. For the case of $\Delta \psi_{1}=60 \mathrm{deg}$, a coarse grid result is also included. The measured properties in Table 3 represent mean values calculated from the instantaneous velocity field results, with outliers removed using criteria defined in Ref. 1. For some $\Delta \psi_{1}$, measurements are not provided since the number of usable instantaneous velocity fields was insufficient to provide meaningful statistics. The computed trends with respect to delayed azimuth follow the measurements, though the computed core radius is close to $100 \%$ larger than the data for some cases. Figure 16 compares the computed and measured location of the vortices in the measurement plane. CAMRAD II calculations using wall corrections (from Ref. 1) are included in addition to the CFD results. The computations bound the measured vertical location of the vortices with the CFD results consistently higher than the measurements. Since the four blades are modeled identically in both CAMRAD II and in the CFD analysis, no distinction is made between the vortices from the simulated blades. The measurements, however, clearly show differences in vortex trajectory between the four blades. Figure 17 shows the comparison between computed and measured vortex circulation. For $\Delta \psi<90 \mathrm{deg}$, the CFD-predicted circulation is too low, indicating the formation and roll-up of the tip vortex likely requires finer grid spacing. For $\Delta \psi>90$ deg, the CFDcomputed circulation is within the bounds of the measurements. The CAMRAD II results, as explained in Ref. 1, are based on the assumption that the trailed vorticity is completely entrained within $60 \mathrm{deg}$ of wake age at the tip. The 
secondary inboard vortex identified as "V" in Figs. 11a)-15a) is not modeled by CAMRAD II, which explains why the CAMRAD II results over-predict the circulation.

\begin{tabular}{|c|c|c|c|c|c|c|}
\hline Blade & $\begin{array}{c}\Delta \psi_{\mathbf{n}} \\
\text { (deg ) } \\
\text { n=blade } \\
\text { number }\end{array}$ & $\begin{array}{c}\text { mean } \\
\text { xc }(\mathrm{mm})\end{array}$ & $\begin{array}{c}\text { mean } \\
\text { yc }(\mathrm{mm})\end{array}$ & $\begin{array}{c}\text { mean } \\
\text { rc } \\
(\mathrm{mm})\end{array}$ & $\begin{array}{c}\text { mean } \\
\Gamma \\
\left(\mathrm{m}^{2} / \mathrm{s}\right)\end{array}$ & Comment \\
\hline 1 & 5 & -89.8 & 20.1 & 55.9 & 11.2 & Experiment* \\
\hline 1 & 15 & -26.5 & 146.2 & 52.1 & 7.5 & $\mathrm{CFD} / 5 \%$ \\
\hline 1 & 30 & -35.3 & 130.9 & 50.4 & 10.6 & Experiment* \\
\hline 1 & 45 & -56.4 & 185.0 & 43.2 & 9.3 & Experiment* \\
\hline 1 & 45 & -43.3 & 300.1 & 59.0 & 7.2 & $\mathrm{CFD} / 5 \%$ \\
\hline 1 & 60 & -72.8 & 234.1 & 37.6 & 7.8 & Experiment* \\
\hline 1 & 60 & -72.3 & 361.3 & 60.9 & 7.0 & $\mathrm{CFD} / 5 \%$ \\
\hline 1 & 60 & -32.2 & 286.2 & 98.4 & 8.9 & $\mathrm{CFD} / 10 \%$ \\
\hline 1 & 75 & -120.4 & 270.5 & 39.3 & 8.0 & Experiment* \\
\hline 1 & 75 & -111.7 & 419.4 & 62.6 & 6.8 & $\mathrm{CFD} / 5 \%$ \\
\hline 1 & 95 & -215.8 & 319.0 & 42.7 & 8.1 & Experiment* \\
\hline 1 & 185 & -945.0 & 398.2 & 37.4 & 4.7 & Experiment* \\
\hline 2 & 5 & -72.7 & 3.5 & 48.3 & 10.7 & Experiment* \\
\hline 2 & 95 & -257.4 & 307.1 & 44.1 & 7.0 & Experiment* \\
\hline 2 & 185 & -1001.0 & 527.8 & 35.7 & 4.1 & Experiment* \\
\hline 3 & 5 & -101.8 & -12.5 & 55.7 & 12.5 & Experiment* \\
\hline 3 & 95 & -247.5 & 389.0 & 37.6 & 7.1 & Experiment* \\
\hline 3 & 185 & -988.6 & 545.3 & 30.3 & 4.1 & Experiment* \\
\hline 3 & 195 & 1105.1 & 644.0 & 70.0 & 4.5 & $\mathrm{CFD} / 5 \%$ \\
\hline 3 & 210 & -1239.0 & 519.3 & 30.2 & 3.9 & Experiment* \\
\hline 3 & 225 & 1491.4 & 632.4 & 73.2 & 4.1 & $\mathrm{CFD} / 5 \%$ \\
\hline 3 & 240 & 1615.7 & 466.8 & 34.0 & 3.1 & Experiment \\
\hline 3 & 240 & 1708.1 & 621.0 & 74.2 & 3.7 & $\mathrm{CFD} / 5 \%$ \\
\hline 3 & 255 & 1871.2 & 442.6 & 30.3 & 2.4 & Experiment* \\
\hline 3 & 255 & 1947.5 & 609.3 & 69.8 & 3.2 & $\mathrm{CFD} / 5 \%$ \\
\hline 4 & 5 & -97.3 & 47.1 & 53.0 & 10.0 & Experiment* \\
\hline 4 & 95 & -236.4 & 394.0 & 36.9 & 5.2 & Experiment* \\
\hline 4 & 105 & -275.3 & 495.3 & 65.8 & 6.0 & $\mathrm{CFD} / 5 \%$ \\
\hline 4 & 120 & -361.5 & 437.2 & 27.4 & 3.5 & Experiment \\
\hline 4 & 135 & -487.9 & 567.5 & 69.0 & 5.6 & $\mathrm{CFD} / 5 \%$ \\
\hline 4 & 150 & -586.8 & 524.0 & 33.2 & 4.5 & Experiment* \\
\hline 4 & 150 & -615.4 & 595.6 & 72.3 & 5.3 & $\mathrm{CFD} / 5 \%$ \\
\hline 4 & 165 & -733.3 & 555.0 & 36.7 & 4.8 & Experiment* \\
\hline 4 & 165 & -755.9 & 623.7 & 73.5 & 5.1 & $\mathrm{CFD} / 5 \%$ \\
\hline
\end{tabular}

*From Table 2 of Ref. 1 (vortex properties extracted from instantaneous velocity fields and then averaged) $\mathrm{CFD} / 5 \%$ : refers to fine grid with L1 spacing of 5\%Ctip.

$\mathrm{CFD} / 10 \%$ : refers to medium grid with L1 spacing of 10\%Ctip.

Table 3. Computed and measured vortex properties: Run 73, $\mathrm{M}_{\mathrm{tip}}=0.65, \mu=0.15$ 


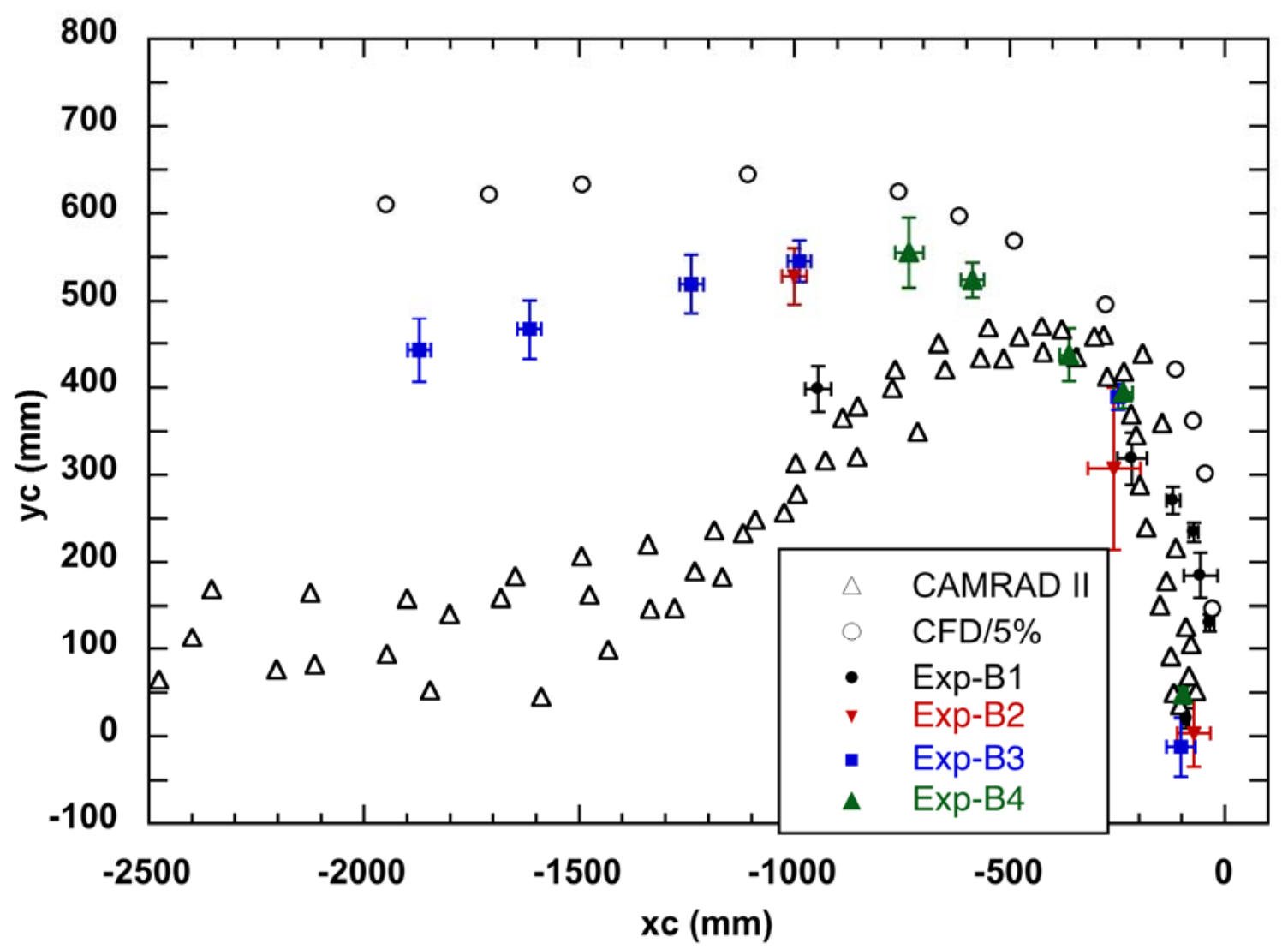

Figure 16. Predicted and measured tip vortex trajectories for Run 73. CAMRAD II results (with wall corrections) and measurements are from Ref. 1 (error bars represent \pm one standard deviation). CFD/5\%: refers to fine grid with L1 spacing of $5 \%$ Ctip. 


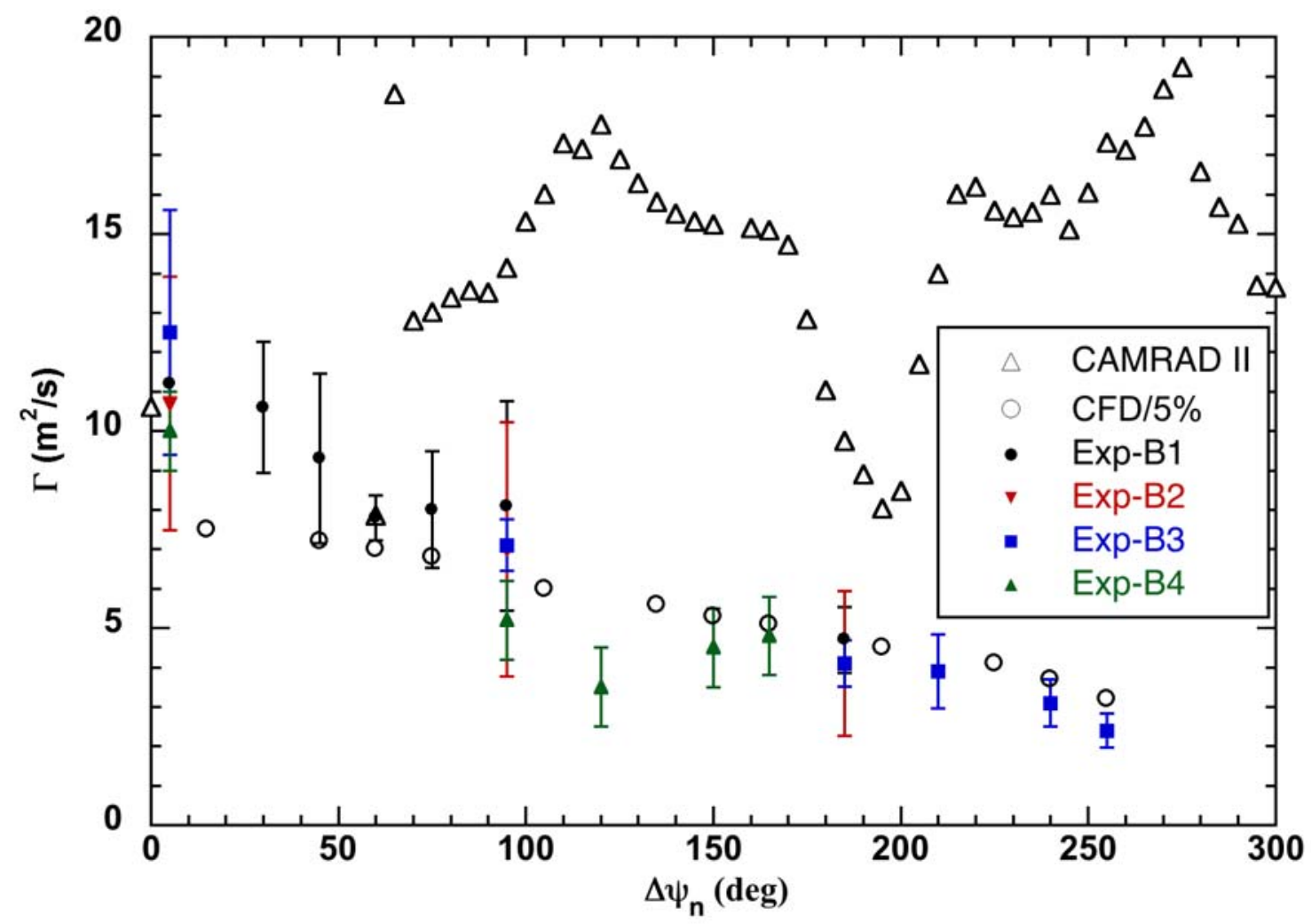

Figure 17. Predicted and measured tip vortex circulation for Run 73. CAMRAD II results (with wall corrections) and measurements are from Ref. 1 (error bars represent \pm one standard deviation). CFD/5\%: refers to fine grid with L1 spacing of 5\%Ctip.

Figure 18 compares the computed and measured vorticity field for Blade 1 at a delayed azimuth of $60 \mathrm{deg}$. The computed vorticity field is shown for both spatial resolution of $10 \% \mathrm{C}_{\text {tip }}$ and $5 \% \mathrm{C}_{\text {tip }}$ for the background Cartesian grid. The computations for both spatial resolutions show the presence of the shear layer surrounding the core; in the experiment the shear layer is not evident. Both spatial resolutions show very weak vorticity near the core indicating insufficient grid resolution. This insufficient grid resolution also resulted in a highly dissipated vorticity field. The $5 \%$ spatial resolution case shows noticeable improvement from the coarse mesh.

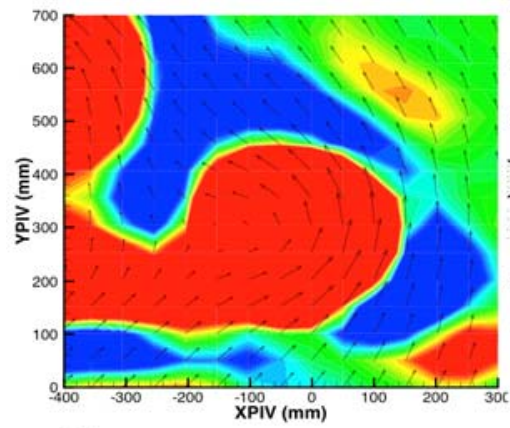

(a)

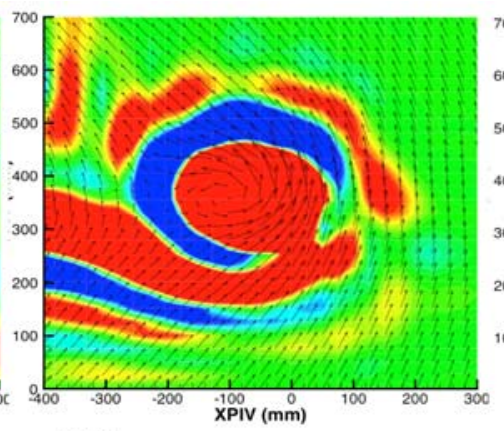

(D)

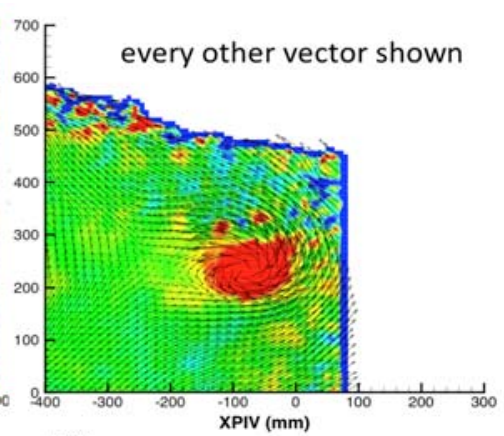

(c)

Figure 18. Comparison of vorticity (inplane component) fields generated by Blade 1 at $\Delta \psi_{4}=60^{\circ}$. (a). Computed with background mesh at $10 \% \mathrm{C}_{\text {tip }}$ (b). Computed with background mesh at $5 \% \mathrm{C}_{\text {tip }}$ (c). Experiment: Run 73. 


\section{Summary}

A simulation using the time-accurate Navier-Stokes OVERFLOW analysis loosely coupled with the comprehensive code CAMRAD II was presented for an isolated full-scale UH-60A rotor in forward flight. The computational details of the vortex dynamics and evolution were compared with wind tunnel test data. The analyses and experimental setup are briefly discussed. Time step and subiteration sensitivity of the simulation were assessed. A limited grid sensitivity study was also conducted. Space-time resolution issue is addressed. Two different turbulence models were used for assessing differences in the prediction. Comparisons between computed and measured blade airloads were made for one radial section where BVI events were predicted. Both qualitative and quantitative comparisons of the computed and measured flow field reveal that the simulation captures the key features of the complex rotor wake. Although the simulation captures the measured BVI events represented in the blade section airloads, the present grid resolution is not adequate for predicting vortex properties, especially, at small delayed azimuth. However, the computed vortex property trends agree with the measured trends. A grid resolution similar to PIV resolution is prohibitive, however, putting 10 or more points across the vortex using grid adaption is a future option.

\section{Acknowledgements}

This task was funded by the NASA Rotary Wing Project. The authors thank Mr. Timothy Sandstrom for his help with some of the visualization figures. The authors also thank Dr. Manikandan Ramasamy for his helpful discussion regarding vortex property extraction. This work utilized NASA Advanced Supercomputing (NAS) division facilities including the Pleiades supercomputer.

\section{References}

${ }^{1}$ Yamauchi, G. K., Wadcock, A., Johnson, W., and Ramasamy, M., "Wind Tunnel Measurements of Full-Scale UH-60A Rotor Tip Vortices," American Helicopter Society $68^{\text {th }}$ Annual Forum, Ft. Worth, TX, May 1-3, 2012.

${ }^{2}$ Ahmad, J. U., Chaderjian, N. M., "High-Order Accurate CFD/CSD Simulation of the UH60 Rotor in Forward Flight," AIAA-2011-3185, $29^{\text {th }}$ Applied Aerodynamics Conference, Honolulu, HI, June 27-30, 2011.

${ }^{3}$ Chaderjian, N. M., Ahmad, J. U. "Detached Eddy Simulation of the UH-60 Rotor Wake Using Adaptive Mesh Refinement," American Helicopter Society $68^{\text {th }}$ Annual Forum, Ft. Worth, TX, May 1-3, 2012.

${ }^{4}$ Nichols, R., and Buning, P., "User's Manual for OVERFLOW 2.1," University of Alabama at Birmingham, Birmingham, AL 35294. 2010.

${ }^{5}$ Norman, T. R.,Peterson R. L., Shinoda, P., and Datta, A. "Full -Scale Wind Tunnel Test of the UH-60A Airloads Rotor," American Helicopter Society $67^{\text {th }}$ Annual Forum, Virginia Beach, VA, May 3-5, 2011.

${ }^{6}$ Wadcock, A., Yamauchi, G. K., Solis, E., and Pete, A., "PIV Measurements in the Wake of a Full-Scale Rotor in Forward Flight," AIAA Paper 2011-3370, $29^{\text {th }}$ AIAA Applied Aerodynamics Conference, Honolulu, HI, June 2011.

${ }^{7}$ Johnson, W., "Rotorcraft Aerodynamic Models for a Comprehensive Analysis," American Helicopter Society 54th Annual Forum, Washington, D.C., May 1998.

${ }^{8}$ Chan, W. M., "Developments in Strategies and Software Tools for Overset Structured Grid Generation and Connectivity", AIAA-2011-3051, AIAA 20th Computational Fluid Dynamics Conference, Honolulu, Hawaii, June 27-30, 2011.

${ }^{9}$ Harten, A., Lax, P. D., and van Leer, B., "On Upstream Differencing and Godunov-type Schemes for Hyperbolic Conservation Laws," SIAM Review, Vol. 25, No. 1, 1983, pp. 35-61.

${ }^{10}$ Toro, E. F., Spruce, M., and Speares, W., "Restoration of the Contact Surface in the HLL Riemann Solver," Shock Waves, Vol. 2, 1994, pp. 25-34.

${ }^{11}$ Nichols, R., Trammel, R., and Buning, P., "Solver and Turbulence Model Upgrades to OVERFLOW 2 for Unsteady and High-Speed Flow Applications," AIAA-2006-2824, June 2006.

${ }^{12}$ Spalart, P. R., and Allmaras, S. R., "A One-Equation Turbulence Model for Aerodynamic Flows,” AIAA Paper 92-0439, January 1992.

${ }^{13}$ Menter, F. R., "Zonal Two-Equation $k-\omega$ Turbulence Model for Aerodynamic Flows," AIAA Paper 19932906, 1993.

${ }^{14}$ Spalart, P. R., Jou, W-H., Strelets, M., and Allmaras, S. R., "Comments on the Feasibility of LES for Wings and on a Hybrid RANS/LES Approach," First AFOSR Conference on DNS/LES, August 1997, Greyden Press, Columbus, $\mathrm{OH}$.

${ }^{15}$ H. van der Ven, “An adaptive multitime multigrid algorithm for time-periodic flows,” JCP 227, 5286-5303, 
2008.

${ }^{16}$ Lim, J.W., Wissink, A., Jayaraman, B., and Dimanlig, A., "Helios Adaptive Mesh Refinement for Hart II Rotor Wake Simulation," American Helicopter Society $68^{\text {th }}$ Annual Forum, May 1-3, 2012, Ft. Worth, Texus.

${ }^{17}$ Lim, J. W., and Strawn, R. C., "Computational Modeling of HART II Blade-Vortex Interaction Loading and Wake System," Journal of Aircraft, Vol. 45, No. 3, May-June 2008, pp. 923-933.

${ }^{18}$ van der Wall, B. G. and Richard, H., "Analysis methodology for 3C-PIV data of rotary wind vortices," Experiments in Fluids, (2006) 40: 798-812, DOI 10.1007/s00348-006-0117-x.

${ }^{19}$ Ramasamy, M., Paetzel, R., and Bhagwat, M. J., "Aperiodicity Correction for Rotor Tip Vortex Measurements," American Helicopter Society $67^{\text {th }}$ Annual Forum, Virginia Beach, VA, May 2011.

${ }^{20}$ Bhagwat, M. J. and Ramasamy, M., "Tip Vortex Aperiodicity Correction: Removing Systematic Uncertainty in Core Radius due to Random Uncertainty in Position," $37^{\text {th }}$ European Rotorcraft Forum, Ticino Park, Italy, September 2011. 